\title{
High Capacity of Lithium-Sulfur Batteries at Low Electrolyte/Sulfur Ratio Enabled by An Organosulfide Containing Electrolyte
}

Shuru Chen, Yue Gao, Zhaoxin Yu, Mikhail L. Gordin, Jiangxuan Song, and Donghai Wang*

Department of Mechanical and Nuclear Engineering, The Pennsylvania State University, University Park, PA 16802

*Corresponding author. Tel.: +1 8148631287; fax: +1 8148634848.

E-mail: dwang@psu.edu (D. Wang)

Keywords: Batteries, Dimethyl disulfide, Lithium-sulfur, Electrolyte/sulfur ratio, High sulfur loading

Abstract: Lithium-sulfur (Li-S) battery is a promising energy storage technology to replace lithium ion batteries for higher energy density and lower cost. Dissolution of lithium polysulfide intermediates in conventional Li-S electrolytes is known as one of the key technical barriers to the development of Li-S, because it promotes redistribution and irreversible deposition of $\operatorname{Li}_{2} \mathrm{~S}$, and also forces large amounts of electrolyte to be used, shortening cycling life and driving down cell energy density. Recently, dimethyl disulfide as a functional co-solvent has been demonstrated to show an alternate electrochemical reaction pathway for sulfur cathodes by the formation of dimethyl polysulfides and lithium organosulfides as intermediates and reduction products. In this work, comprehensive studies show that this new pathway not only provides high capacity but also enables excellent capacity retention through a built-in automatic discharge shutoff mechanism by tuning carbon/sulfur ratio in sulfur cathodes to reduce unfavorable $\operatorname{Li}_{2} \mathrm{~S}$ formation. Furthermore, this new electrolyte system is also found to enable high capacity of high-sulfur-loading cathodes with low electrolyte/sulfur (E/S) ratios, such as a stable specific capacity of around $1000 \mathrm{mAh} \mathrm{g}^{-1}$ using a low electrolyte amount (i.e, E/S ratio of $5 \mathrm{~mL} \mathrm{~g}^{-1}$ ) and high-sulfur-loading $\left(4 \mathrm{mg} \mathrm{cm}^{-2}\right)$ cathodes. This electrolyte system almost doubles the capacity obtained with conventional electrolytes under the same harsh conditions. These results highlight the practical potential of this electrolyte system to enable high-energy-density Li-S batteries. 


\section{Introduction}

Rechargeable Li-S batteries are considered as a promising next-generation energy storage system and have received increasing attention in recent years due to their high theoretical energy density, and the use of low-cost, naturally abundant and non-toxic sulfur cathodes [1]. Despite the considerable advantages, the applications of Li-S batteries remain hindered by critical performance drawbacks such as low practical energy density, low Coulombic efficiency, fast capacity degradation, and severe self-discharge. The major reasons for these issues have long been ascribed to several fundamental challenges, such as the poor conductivity of sulfur and its reduction products, the dissolution and side-reactions of lithium polysulfide intermediates, and the irreversible deposition of $\mathrm{Li}_{2} \mathrm{~S}$ on the cathode $[2,3]$.

To address these challenges, great efforts have been made focusing on the design of advanced porous carbon-sulfur (C-S) composites cathodes, which enhance the overall conductivity and help to trap the active materials within the porous carbon matrix [4-11]. However, this approach does not solve the issues intrinsically, especially for dissolution and diffusion of lithium polysulfides out of cathode that is inevitable in liquid electrolytes [12]. Additional approaches have thus been developed, in parallel to the development of the advanced sulfur cathodes, to effectively mitigate polysulfide loss and lead to improved cycling performance. The approaches include electrolyte additives [13-15], optimized electrolytes with low polysulfides solubility [16, 17], new cell configurations with polysulfides blocking interlayers or separators [18-20], protected lithium anodes [21-23], and new recharge technique with constrained charge capacity [24].

Despite significant process, it has been pointed out that specific capacity or sulfur utilization, cycle stability and energy density of Li-S batteries can be significantly influenced by many parameters like the sulfur content/areal loading in the cathode, amount of electrolyte, lithium excess and cycling rate [25]. To obtain a high energy density, both the sulfur content/loading and sulfur utilization should be as high as possible [26], along with a low electrolyte/sulfur (E/S in $\mathrm{mL} \mathrm{g}^{-1}$ ) ratio [27]. Recently, some efforts have been made to use more realistic sulfur loadings and demonstrate a few approaches to achieve high areal capacity with acceptable cycle life [2831]. Unfortunately, much more electrolyte is still required in Li-S batteries compared to conventional LIBs (over 30\% of the cell's weight vs. below 10\%, respectively), as demonstrated in Li-S prototypes, which significantly reduces their practical energy densities [32]. Such a large 
electrolyte amount is used partially because the porosity of C-S cathodes is typically high to sustain active material volume change, resulting in a high electrolyte uptake [26]. In addition, excess of electrolyte is needed to avoid quick electrolyte depletion due to the unstable lithium anode/electrolyte interphase [33]. More importantly, it was found that dissolution of polysulfides can remarkably increase electrolyte viscosity and resistance, leading to poor redox kinetics and low utilization of sulfur cathodes at low E/S ratios [27]. Due to these factors, a high E/S is usually needed to maintain acceptable capacity/rate capability and cycling performance, and therefore most publications that report their E/S ratio used a value of 10 or higher [34-36]. High capacity with high-sulfur-loading cathodes and an E/S ratio of 5 or lower, to the best of our knowledge, is challenging to achieve.

Recently we reported a novel functional electrolyte system using dimethyl disulfide (DMDS) as a co-solvent to promote an alternate electrochemical reaction pathway for sulfur cathodes by formation of dimethyl polysulfide (DMPS) and lithium organosulfides as new redox intermediates and boost the capacity of Li-S cells [37]. However, there are still several important scientific questions on the new electrolyte system attractive to be answered for addressing key technical issues of Li-S batteries, such as, what are the key parameters of sulfur cathode on the effect of performance in this electrolyte, can this electrolyte promote using low amount of electrolyte to achieve high capacity, and how to optimize them to further improve its practical performance. In this paper, we comprehensively evaluate this new electrolyte, aiming to achieve high capacity of Li-S batteries, using different sulfur cathodes with various conditions such as C$\mathrm{S}$ cathodes with various sulfur contents, high areal sulfur loading and low E/S ratio. Enabled by the new mechanism in DMDS-containing electrolyte, interestingly, it is found that the discharge process of sulfur cathodes can shut off by reaching the cut-off voltage at different degrees of depth of discharge by tuning sulfur content (i.e., $\mathrm{C} / \mathrm{S}$ ratio) in the cathode, due to the conductive surface passivation by varied precipitates of reduction products of DMPS intermediates. The cathodes with high sulfur content (low $\mathrm{C} / \mathrm{S}$ ratio) produce ultimately more lithium organosulfides with better redox kinetics and reversibility, creating an automatic shutoff mechanism for the discharge process to mitigate the detrimental irreversible formation of insoluble $\mathrm{Li}_{2} \mathrm{~S}$. It not only allows for excellent cyclability of sulfur cathodes with high sulfur contents, but also shows a high capacity owing to the DMDS-induced capacity contribution. Moreover, the new reaction pathway in DMDS-containing electrolyte avoids the formation and dissolution of viscosity- 
raising long-chain lithium polysulfides and thus enables high capacity with less amount of electrolyte. For example, when a low $\mathrm{E} / \mathrm{S}$ ratio of 5 and high-sulfur-loading $\left(4 \mathrm{mg} \mathrm{cm}^{-2}\right)$ cathodes were used, cells with this new electrolyte system can achieve high stable sulfur-specific capacities of around $1000 \mathrm{mAh} \mathrm{g}^{-1}$, which almost double the value obtained in conventional Li-S electrolyte under the same conditions. These findings demonstrate the great promise of this DMDS-containing electrolyte system for future practical applications.

\section{Material and methods}

Sulfur cathode materials were made by thermal treatment of elemental sulfur and carbon mixtures at $159{ }^{\circ} \mathrm{C}$ in sealed vials for $10 \mathrm{~h}$. Two types of carbon, ordered mesoporous carbon (OMC) synthesized according to a previous report [7] and commercial Ketjenblack EC-600JD $(\mathrm{KB})$, were used as conductive frameworks. The composites were combined with Super P carbon and PVDF as a binder in a mass ratio of 80:10:10 or 70:20:10 for low- $\left(\sim 1 \mathrm{mg} \mathrm{cm}^{-2}\right)$ or high- $(\sim 4$ $\mathrm{mg} \mathrm{cm}{ }^{-2}$ ) sulfur-loading electrodes, respectively, and stirred into a slurry with n-methyl-2pyrrolidone (NMP). The slurry was then blade cast onto carbon-coated aluminum foil and vacuum dried overnight at $55^{\circ} \mathrm{C}$. After drying under vacuum, the electrodes were pressed at 15 $\mathrm{MPa}$, punched into round pieces with diameter of $12 \mathrm{~mm}$, and assembled into CR2016 coin cells with exactly controlled amount of electrolyte and lithium foil as anode in an Ar-filled glove box with $\mathrm{H}_{2} \mathrm{O}$ and $\mathrm{O}_{2}$ level below $0.1 \mathrm{ppm}$. Cycling performance was carried out on an Arbin BT2000 or Land CT2001A battery tester from 1.6 to $2.6 \mathrm{~V}$.

The conventional electrolyte was composed of $0.1 \mathrm{M} \mathrm{LiNO}_{3}$ additive and $1 \mathrm{M}$ lithium bis(trifluoromethanesulfonyl) imide (LiTFSI) in 1,2-dimethoxyethane (DME) and 1,3-dioxolane (DOL) $(\mathrm{v} / \mathrm{v}, 1: 1)$. The $50 \mathrm{vol} \%$ DMDS-containing electrolytes were prepared similarly by dissolving $0.1 \mathrm{M} \mathrm{LiNO}_{3}$ and $1 \mathrm{M} \mathrm{LiTFSI}$ in a mixed solvent of DMDS, DME, and DOL ( $\mathrm{v} / \mathrm{v} / \mathrm{v}$, $2: 1: 1)$. The ionic conductivity of the conventional and $50 \mathrm{vol} \%$ DMDS-containing electrolyte is $\sim 10$ and $5 \mathrm{mS} \mathrm{cm}^{-1}$ at room temperature, respectively. To improve the cycling efficiency, $0.4 \mathrm{M}$ $\mathrm{LiNO}_{3}$ was added to the electrolytes used for high-areal-capacity cells. Note that $0.4 \mathrm{M} \mathrm{LiNO}_{3}$ did not completely dissolve in the $50 \mathrm{vol} \%$ DMDS-containing electrolyte, so it actually contains the amount of $\mathrm{LiNO}_{3}$ needed to achieve saturation.

\section{Results and Discussion}


3.1 Effect of carbon/sulfur ratio on electrochemical performance and automatic shutoff mechanism

To study the influence of $\mathrm{C} / \mathrm{S}$ ratio on electrochemical performance, three OMC-S composite cathodes with different sulfur fractions (40, 50 and $70 \mathrm{wt} \%)$, labeled as OMC-S40, -S50, and S70 were tested in the 50 vol\% DMDS-containing electrolyte. All of these cells again contained $\sim 1 \mathrm{mg}$ of sulfur and $10 \mu \mathrm{L}$ of electrolyte, so only the ratio of carbon to sulfur and DMDS was changed. The OMC-S40, -S50 and -S70 cathodes show initial sulfur-specific capacities of 2485, 1950 and $1361 \mathrm{mAh} \mathrm{g}^{-1}$ (Figure 1a). It is interesting that low C/S ratio (e.g., OMC-S70) allows for a moderate sulfur-specific capacity with excellent capacity retention while increasing carbon fraction (e.g., OMC-S40) greatly increases the sulfur-specific capacity but leads to much worse capacity retention (Figure $1 \mathrm{~b}$ ). Since increasing $\mathrm{C} / \mathrm{S}$ ratio results in more dead weight from inactive carbon, there should be a balance between $\mathrm{C} / \mathrm{S}$ ratio and the sulfur-specific capacity. As shown in Figure 1c and 1d, if the whole mass of OMC-S composite was used to re-calculate the specific capacity, the three cathodes show similar initial capacity of $\sim 1000 \mathrm{mAh} \mathrm{g}^{-1}$ per composite and OMC-S70 delivers the best overall performance. In contrast, tuning the carbon fraction has little effect on the sulfur-specific capacity and capacity retention in conventional electrolyte, as all the cathodes show similar initial sulfur-specific capacities of $\sim 1200 \mathrm{mAh} \mathrm{g}^{-1}$ (thus lower composite-specific capacity with increasing $\mathrm{C} / \mathrm{S}$ ratio), have fast capacity fading during the first 1-10 cycles, and then stabilize at a low sulfur-specific capacity of $\sim 500-700 \mathrm{mAh}$ $\mathrm{g}^{-1}$ (Figure 2). 

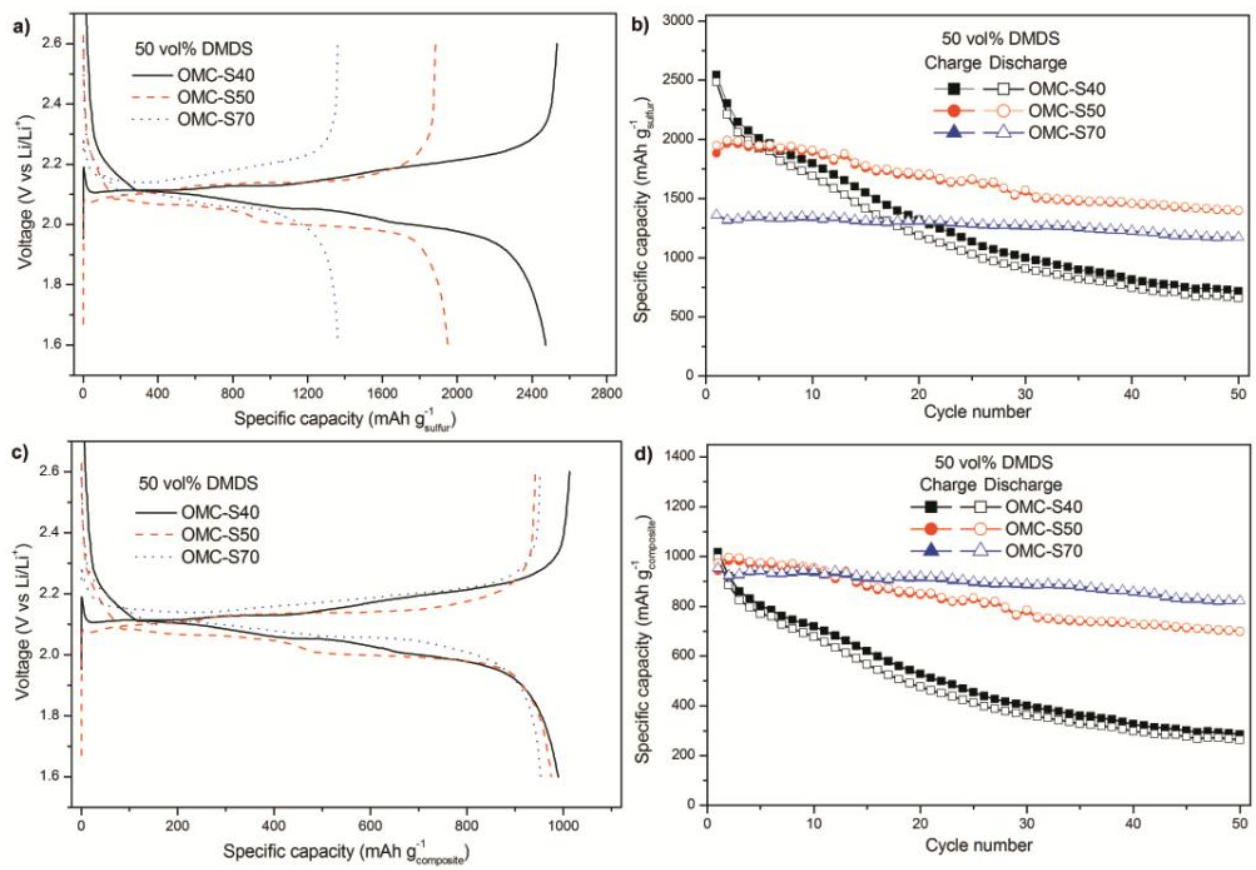

Figure 1. (a, c) Discharge-charge profiles and (b, d) cycling performance of OMC-S40, OMCS50, and OMC-S70 cathodes in $10 \mu \mathrm{L}$ of 50 vol\% DMDS-containing electrolyte at C/10 rate. (a, b) Specific capacity based on sulfur in cathodes; (c, d) specific capacity based on OMC-S composites.
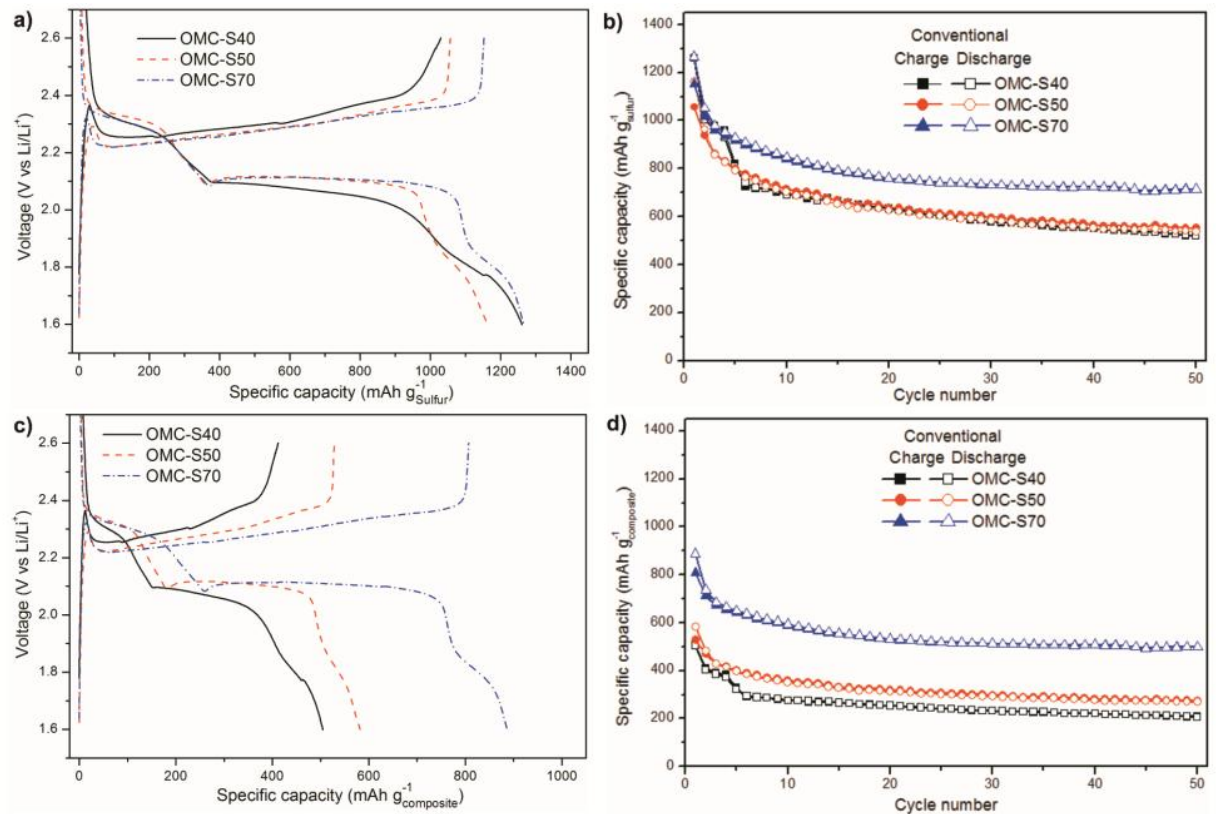

Figure 2. (a, c) Discharge-charge profiles and (b, d) cycling performance of OMC-S40, OMCS50, and OMC-S70 cathodes in $10 \mu \mathrm{L}$ of conventional electrolyte at C/10 rate. (a, b) Specific capacity based on sulfur in cathodes; (c, d) specific capacity based on OMC-S composites. 
This major difference in behavior between the conventional and DMDS-containing electrolyte systems stems from the new reduction pathway in DMDS-containing electrolyte, which proceeds mainly through the formation and subsequent multi-step reduction of DMPS species to lithium organosulfides, and ultimately forms $\mathrm{CH}_{3} \mathrm{SLi}$ and $\mathrm{Li}_{2} \mathrm{~S}$. According to our previous NMR results [37], the DMPS intermediates are mainly composed of DMTS and dimethyl tertrasulfide (DMTtS), which, upon complete reduction involve the transfer of 4 and $3 \mathrm{e}^{-}$per sulfur reacting with DMDS, or a maximum specific capacity of 3350 and $2515 \mathrm{mAh} \mathrm{g}^{-1}$ based on solid sulfur in the cathode, respectively.

Discharge of sulfur cathodes with low $\mathrm{C} / \mathrm{S}$ ratio ends at a relatively low sulfur-specific capacity (i.e., $\sim 1400 \mathrm{mAh} \mathrm{g}^{-1}$ per sulfur initially for OMC-S70, equaling to $42 \%$ or $56 \%$ utilization of DMTS or DMTtS, respectively), because lithium organosulfides (especially $\mathrm{CH}_{3} \mathrm{SSLi}$ and $\mathrm{CH}_{3} \mathrm{SLi}$ ) show limited solubility only in the electrolyte (see Figure $\mathrm{S} 1$ ) and thus deposit on and passivate the conductive surface, preventing further reduction of themselves to form insoluble $\mathrm{Li}_{2} \mathrm{~S}$ (schematically illustrated in Figure $3 \mathrm{~b}$ ). Since increasing $\mathrm{C} / \mathrm{S}$ ratio provides more conductive surface for the interfacial reactions of DMPS intermediates and also significantly enhances the electrical conductivity of the cathode, it is understandable that the use of sulfur cathodes with high $\mathrm{C} / \mathrm{S}$ ratios can enable the reduction of more amounts of lithium organosulfides to the $\mathrm{CH}_{3} \mathrm{SLi}$ and $\mathrm{Li}_{2} \mathrm{~S}$ (schematically illustrated in Figure 3c), leading to a much higher sulfur-specific capacity (i.e., $2500 \mathrm{mAh} \mathrm{g}^{-1}$ per sulfur initially for OMC-S40, equaling to $75 \%$ or $99 \%$ utilization of DMTS or DMTtS, respectively). However, the formation of a large amount of $\mathrm{Li}_{2} \mathrm{~S}$ and $\mathrm{CH}_{3} \mathrm{SLi}$ in this case may also cause more irreversible $\mathrm{Li}_{2} \mathrm{~S}$ agglomeration on the cathode, which is a well-documented reason for capacity fading of sulfur cathodes [3]. Additionally, while lithium polysulfides can assist the dissolution and utilization of $\mathrm{Li}_{2} \mathrm{~S}$ during cell charging [38], DMDS and DMTS were not found to enable dissolution of $\mathrm{Li}_{2} \mathrm{~S}$ (see Figure $\mathrm{S} 2$ ) - this is believed to make utilization of $\mathrm{Li}_{2} \mathrm{~S}$ less reversible in the sulfur/DMDS-containing electrolyte system, and accounts for the stronger dependence of cyclability on sulfur-specific capacity. 

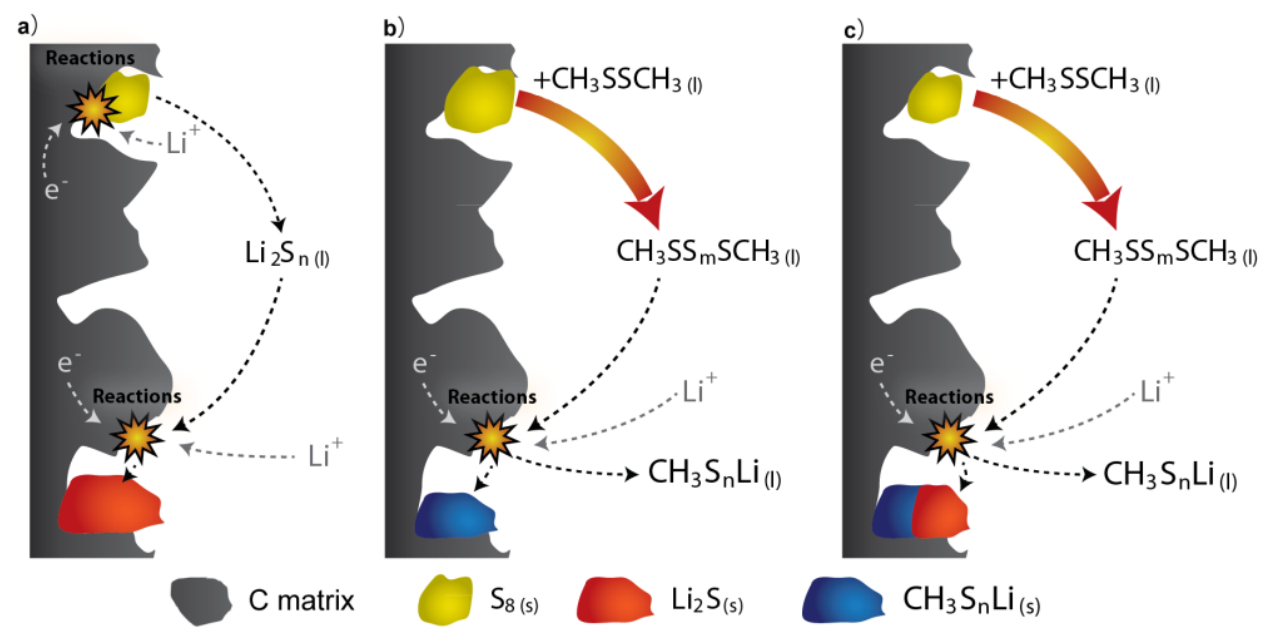

Figure 3. Schematic diagrams of the discharge mechanism of surface species at the surface of carbon materials in (a) conventional ether-based Li-S electrolytes and (b, c) DMDS-containing electrolytes with tuned low (b) and high (c) C/S ratios in the cathodes, showing the shutoff of the discharge process due to electrode surface passivation by different solid precipitates.

Despite the limited solubility, lithium organosulfides are still much more soluble and thus more reactive than insoluble $\mathrm{Li}_{2} \mathrm{~S}$, making them comparatively less difficult to delithiate during charging. The low solubility of lithium organosulfides also suggests that they may not increase the viscosity of the electrolyte much during discharging of the sulfur cathodes. This could allow a lower E/S ratio to be used, as demonstrated below. The buildup of lithium organosulfides in the carbon framework at a low $\mathrm{C} / \mathrm{S}$ ratio (e.g., OMC-S70) thus serves as a safe automatic shutoff for the sulfur cathodes, avoiding the formation of a large amount of $\mathrm{Li}_{2} \mathrm{~S}$ and enabling excellent cycling stability. Such a safe shutoff mechanism is not observed with conventional electrolyte (Figure 3), as that system has no similar equivalent to lithium organosulfides and discharge only ends upon surface passivation by insoluble $\mathrm{Li}_{2} \mathrm{~S}$ [39], as schematically illustrated in Figure 3a. Constraining the depth of discharge (e.g., $<50 \%$ sulfur utilization or $834 \mathrm{mAh} \mathrm{g}^{-1}$ per sulfur before the formation of $\mathrm{Li}_{2} \mathrm{~S}$ ) in conventional electrolyte has been reported to result in good cycle life of sulfur cathodes, nevertheless, at the expense of capacity [40]. Even though low sulfur utilization (below 50\%) must be also maintained to avoid insoluble $\mathrm{Li}_{2} \mathrm{~S}$ deposition and utilize the safe shutoff mechanism, the DMDS-containing electrolyte system still provides a much higher stable sulfur-specific capacity than the conventional electrolyte system: 1200 mAh $\mathrm{g}^{-1}$ vs. $\sim 700 \mathrm{mAh} \mathrm{g}^{-1}$ respectively, for the OMC-S70 cathode after 50 cycles. This increase comes from the DMDS-induced capacity contribution. Therefore, making full use of the system's built- 
in shutoff mechanism by tuning both the carbon to sulfur and DMDS ratios is critical to achieving a good balance between capacity and cyclability.

3.2 Effect of carbon matrix on electrochemical performance
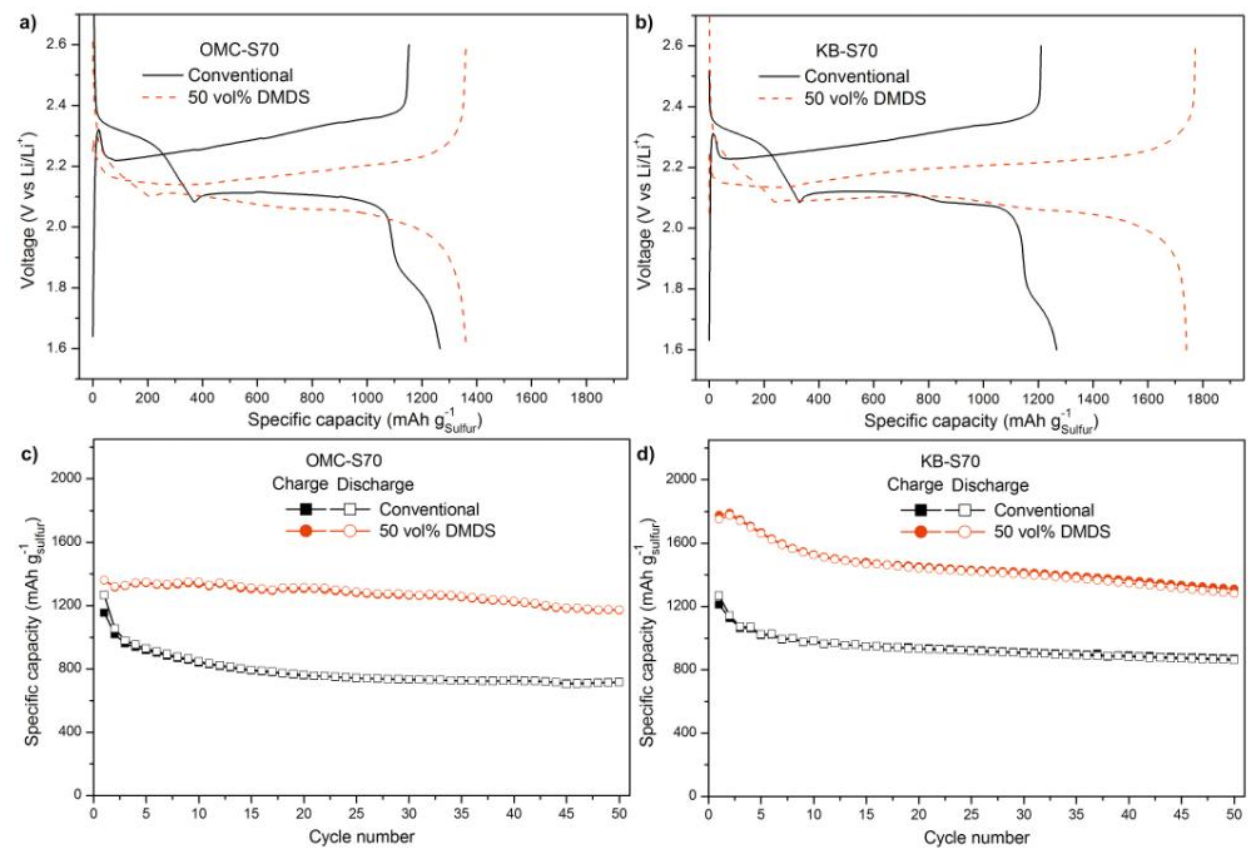

Figure 4. (a, b) Discharge-charge curves and (c, d) cycling performance of (a, c) OMC-S70 and (b, d) KB-S70 cathodes in $10 \mu \mathrm{L}$ of both conventional and 50 vol\% DMDS-containing electrolyte at $\mathrm{C} / 10$ rate.

To study the compatibility of the DMDS-containing electrolyte systems with different type of C-S composite cathodes, $\mathrm{KB}$ carbon was also used to make a C-S composite with $70 \mathrm{wt} \%$ sulfur (KB-S70). As shown in Figure 4, when both the OMC-S70 and KB-S70 composites were tested with conventional electrolyte at $\mathrm{C} / 10$ rate, they delivered similar initial discharge capacity of $\sim 1250 \mathrm{mAh} \mathrm{g}^{-1}$. After 50 cycles, the KB-S70 cathode maintains a slightly higher capacity of $\sim 850$ vs. $\sim 700 \mathrm{mAh} \mathrm{g}^{-1}$ for the OMC-S70 cathode. Such an improvement is most likely due to the excellent electrical conductivity of the KB carbon and higher pore volume (Figure S3). With the 50 vol\% DMDS-containing electrolyte, similar changes in discharge-charge profiles as above observed for OMC-S composite were found in Figure 4b, indicating the similar changes in redox pathway, despite of different C-S composite cathodes. In addition, the discharge capacity of the KB-S70 cathode significantly increases to $\sim 1750 \mathrm{mAh} \mathrm{g}^{-1}$ initially and stabilized at $\sim 1300 \mathrm{mAh}$ $\mathrm{g}^{-1}$ after 50 cycles, which are higher than that achieved with the OMC-S70 cathode. 
3.3 Improved electrochemical performance at low E/S ratios and high sulfur loading

Previous work has demonstrated that high areal capacity is required for cathodes to be practical, as this minimizes the fraction of inactive material in the cell [27]. To demonstrate the potential of the DMDS-containing electrolyte with high-areal-capacity electrodes for practical use, KB-S70 was further used in to make cathodes with a high sulfur loading of $\sim 4 \mathrm{mg} \mathrm{cm}^{-2}$. As shown in Figure 5, these cathodes were tested with conventional and 50 vol\% DMDS-containing electrolyte, as well as with the polysulfide-containing electrolyte which was shown to contribute capacity to Li-S cells, even though for low-sulfur-loading electrodes [40]. When tested with $\mathrm{E} / \mathrm{S}=10$, the cells delivered a discharge capacity of 1136 and $1396 \mathrm{mAh} \mathrm{g}^{-1}$ initially, and a capacity of 729 and $763 \mathrm{mAh} \mathrm{g}^{-1}$ after 25 cycles, with conventional and polysulfide-containing electrolyte, respectively. As expected, the cells with DMDS-containing electrolyte showed much higher capacity, with $1615 \mathrm{mAh} \mathrm{g}^{-1}$ initially and $1366 \mathrm{mAh} \mathrm{g}^{-1}$ after 25 cycles. Since, as mentioned previously, decreasing the $\mathrm{E} / \mathrm{S}$ ratio is of critical importance to practical cell energy density, we also tested cells with $\mathrm{E} / \mathrm{S}=5$. In line with previous results [27, 34], the capacity of cells with conventional electrolyte dropped significantly under these conditions, down to 500$600 \mathrm{mAh} \mathrm{g}^{-1}$. Cells with polysulfide-containing electrolyte had even lower capacity. This poor performance, as well as the mediocre performance even at $E / S=10$, likely stem from the high viscosity of polysulfide-containing electrolyte - not a major issue for low-sulfur-loading cathodes, but a very serious problem at high sulfur loadings and especially with low E/S ratios, as previously noted [27]. In contrast, the DMDS-containing electrolyte enabled cells to maintain good performance at low E/S ratio, with a high capacity of $1319 \mathrm{mAh} \mathrm{g}^{-1}$ initially and $989 \mathrm{mAh}$ $\mathrm{g}^{-1}$ after 25 cycles. This is about a $100 \%$ increase in capacity when compared to the conventional electrolyte system, and is the first report of such a high specific capacity with high sulfur loading and a low $\mathrm{E} / \mathrm{S}$ ratio of 5 . The improvement can be ascribed to the new reaction pathway of sulfur in DMDS-containing electrolyte, which has a better electrochemical kinetics than lithium polysulfides, and seems to allow for high sulfur utilization and/or high capacity contribution from DMDS without running into the same viscosity issue (e.g., viscosity of DMTS is only 1.19 m Pa.s at $20^{\circ} \mathrm{C}$ ). 

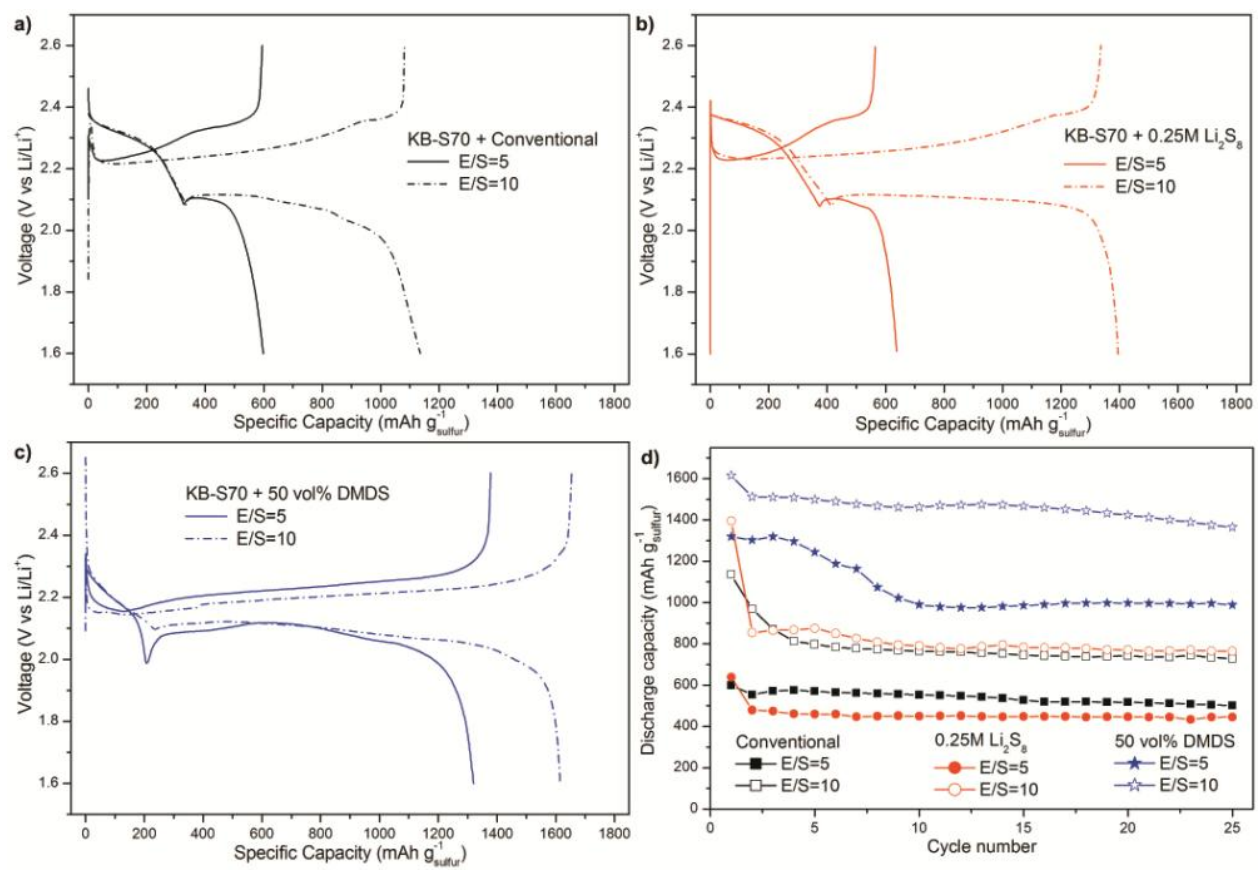

Figure 5. Initial discharge-charge profiles of KB-S70 cathodes in (a) conventional, (b) $0.25 \mathrm{M}$ polysulfide-containing, and (c) 50 vol\% DMDS-containing electrolytes with $\mathrm{E} / \mathrm{S}=5$ and $10 \mathrm{~mL} \mathrm{~g}$ 1 at a current density of $0.2 \mathrm{~mA} \mathrm{~cm}^{-2}$, and (d) their corresponding cycling performance.

In the above discussion we compared electrolyte systems by sulfur-specific capacity; however, in practical cells, other components may contribute mass or capacity to the cells, including electrolyte (active, as DMDS-containing of polysulfide-containing, or inactive, as conventional), current collectors, and other inactive electrode components such as binder and conductive carbon additives. Changes in these components may lead to a higher sulfur-specific capacity, but not necessarily to a better practical energy density. To better judge the practical potential of these electrolytes, we use a different metric called the representative capacity ( $\mathrm{mAh} \mathrm{g}^{-1}$ rep), which is the capacity divided by the total mass of sulfur, carbon, binder, cathode current collector, and electrolyte. As shown in Figure $\mathrm{S} 5$ with $\mathrm{E} / \mathrm{S}=5$, cells using DMDS-containing electrolyte deliver the highest initial and $25^{\text {th }}$-cycle representative capacity of 148 and $111 \mathrm{mAh} \mathrm{g}^{-1}$ rep, respectively; these are more than double the initial and $25^{\text {th }}$-cycle capacities with conventional electrolyte (67 $\mathrm{mAh} \mathrm{g}^{-1}$ rep and $56 \mathrm{mAh} \mathrm{g}_{\text {rep }}^{-1}$, respectively). These results highlight the advantages of DMDScontaining electrolyte compared to the conventional DOL/DME based electrolyte, and its significant potential for high energy-density Li-S batteries. 
As an additional point, we note that after around 25 cycles, the cell efficiency drops dramatically (Figure S5) and capacity fades much more rapidly, especially with $\mathrm{E} / \mathrm{S}=5$. This mainly stems from consumption of $\mathrm{LiNO}_{3}$ and electrolyte depletion due to unstable lithium/electrolyte interphase, all of which are exacerbated by both low electrolyte amount and high areal capacity $[15,25,27,33]$. As an evidence, we tested another cell with $\mathrm{E} / \mathrm{S}=20$ using 50 vol\% DMDS-containing electrolyte which shows enhanced capacity and longer cycle life for at least 100 cycles at $\mathrm{C} / 10$ (Figure S6). These indicate the continued need for improved anode protection in Li-S cells.

\section{Conclusion}

In conclusion, we reported a novel functional electrolyte system using dimethyl disulfide (DMDS) as a co-solvent to promote an alternate electrochemical reaction pathway for sulfur cathodes. The formation and subsequent reduction of new soluble DMPS intermediates upon discharging and re-oxidation of new reduction products like lithium organosulfides not only boost cell capacity, but also enable good cyclability of sulfur cathodes by way of an automatic discharge shutoff behavior. In addition, high-sulfur-loading cathodes $\left(\sim 4 \mathrm{mg} \mathrm{cm}^{-2}\right)$ can cycle in this electrolyte and exhibit a stable specific capacity of around $1000 \mathrm{mAh} \mathrm{g}^{-1}$ per sulfur, even with a low electrolyte/sulfur ratio of 5, reaching almost double the value obtained in conventional Li-S electrolyte under the same harsh conditions. This work thus provides a new strategy for improving the practical energy density of Li-S batteries.

\section{Acknowledgement}

This work was supported by the Assistant Secretary for Energy Efficiency and Renewable Energy, Office of Vehicle Technologies of the U.S. Department of Energy under Contract No. DE-EE0005475 and DE- EE0007795.

\section{References}

[1] P.G. Bruce, S.A. Freunberger, L.J. Hardwick, J.M. Tarascon, Nature Materials, 11 (2012) 1929.

[2] S.S. Zhang, Journal of Power Sources, 231 (2013) 153-162.

[3] C. Barchasz, J.C. Lepretre, F. Alloin, S. Patoux, Journal of Power Sources, 199 (2012) 322330. 
[4] S. Xin, L. Gu, N.H. Zhao, Y.X. Yin, L.J. Zhou, Y.G. Guo, L.J. Wan, Journal of the American Chemical Society, 134 (2012) 18510-18513.

[5] B. Zhang, X. Qin, G.R. Li, X.P. Gao, Energy \& Environmental Science, 3 (2010) 1531-1537.

[6] X.L. Ji, K.T. Lee, L.F. Nazar, Nature Materials, 8 (2009) 500-506.

[7] S.R. Chen, Y.P. Zhai, G.L. Xu, Y.X. Jiang, D.Y. Zhao, J.T. Li, L. Huang, S.G. Sun, Electrochimica Acta, 56 (2011) 9549-9555.

[8] N. Jayaprakash, J. Shen, S.S. Moganty, A. Corona, L.A. Archer, Angewandte ChemieInternational Edition, 50 (2011) 5904-5908.

[9] Y.-X. Wang, L. Huang, L.-C. Sun, S.-Y. Xie, G.-L. Xu, S.-R. Chen, Y.-F. Xu, J.-T. Li, S.-L. Chou, S.-X. Dou, Journal of Materials Chemistry, 22 (2012) 4744-4750.

[10] J. Song, Z. Yu, M.L. Gordin, D. Wang, Nano Letter, 16 (2016) 864-870.

[11] J. Song, M.L. Gordin, T. Xu, S. Chen, Z. Yu, H. Sohn, J. Lu, Y. Ren, Y. Duan, D. Wang, Angewandte Chemie-International Edition, 54 (2015) 4325-4329.

[12] S.S. Zhang, Journal of the Electrochemical Society, 159 (2012) A920-A923.

[13] S.S. Zhang, Electrochimica Acta, 70 (2012) 344-348.

[14] X. Liang, Z.Y. Wen, Y. Liu, M.F. Wu, J. Jin, H. Zhang, X.W. Wu, Journal of Power Sources, 196 (2011) 9839-9843.

[15] A. Rosenman, R. Elazari, G. Salitra, E. Markevich, D. Aurbach, A. Garsuch, Journal of The Electrochemical Society, 162 (2015) A470-A473.

[16] M. Cuisinier, P.E. Cabelguen, B.D. Adams, A. Garsuch, M. Balasubramanian, L.F. Nazar, Energy \& Environmental Science, 7 (2014) 2697-2705.

[17] L.M. Suo, Y.S. Hu, H. Li, M. Armand, L.Q. Chen, Nature Communication, 4 (2013) Article number: 1481.

[18] Y.S. Su, A. Manthiram, Nature Communication, 3 (2012) Article number: 1166.

[19] S.-H. Chung, A. Manthiram, Advanced Functional Materials, 24 (2014) 5299-5306.

[20] J.-Q. Huang, Q. Zhang, H.-J. Peng, X.-Y. Liu, W.-Z. Qian, F. Wei, Energy \& Environmental Science, 7 (2014) 347-353.

[21] Y.M. Lee, N.S. Choi, J.H. Park, J.K. Park, Journal of Power Sources, 119 (2003) 964-972. [22] G. Ma, Z. Wen, M. Wu, C. Shen, Q. Wang, J. Jin, X. Wu, Chemical Communications, 50 (2014) 14209-14212. 
[23] C. Huang, J. Xiao, Y.Y. Shao, J.M. Zheng, W.D. Bennett, D.P. Lu, L.V. Saraf, M.

Engelhard, L.W. Ji, J.G. Zhang, X.L. Li, G.L. Graff, J. Liu, Nature Communication, 5 (2014) Article number: 3015.

[24] Y.-S. Su, Y. Fu, T. Cochell, A. Manthiram, Nature Communication, 4 (2013) Article number: 3985.

[25] J. Brückner, S. Thieme, H.T. Grossmann, S. Dörfler, H. Althues, S. Kaskel, Journal of Power Sources, 268 (2014) 82-87.

[26] M. Hagen, S. Dörfler, P. Fanz, T. Berger, R. Speck, J. Tübke, H. Althues, M.J. Hoffmann, C. Scherr, S. Kaskel, Journal of Power Sources, 224 (2013) 260-268.

[27] M. Hagen, P. Fanz, J. Tübke, Journal of Power Sources, 264 (2014) 30-34.

[28] T. Xu, J. Song, M.L. Gordin, H. Sohn, Z. Yu, S. Chen, D. Wang, ACS Applied Materials \& Interfaces, 5 (2013) 11355-11362.

[29] J. Song, T. Xu, M.L. Gordin, P. Zhu, D. Lv, Y.-B. Jiang, Y. Chen, Y. Duan, D. Wang, Advanced Functional Materials, 24 (2014) 1243-1250.

[30] W. Zhou, B. Guo, H. Gao, J.B. Goodenough, Advanced Energy Materials, 6 (2015) 6: 1502059. doi: 1502010.1501002/aenm.201502059.

[31] J. Song, Z. Yu, T. Xu, S. Chen, H. Sohn, M. Regula, D. Wang, Journal of Materials Chemistry A, 2 (2014) 8623-8627.

[32] Y. Mikhaylik, I. Kovalev, K. Kumaresan, J. Xu, J. Affinito, ECS Transactions, 25 (2010) 23-34.

[33] D. Aurbach, E. Zinigrad, Y. Cohen, H. Teller, Solid State Ionics, 148 (2002) 405-416.

[34] S.S. Zhang, Energies, 5 (2012) 5190-5197.

[35] J. Zheng, D. Lv, M. Gu, C. Wang, J.-G. Zhang, J. Liu, J. Xiao, Journal of Electrochemical Society, 160 (2013) A2288-A2292.

[36] S. Urbonaite, P. Novák, Journal of Power Sources, 249 (2014) 497-502.

[37] S. Chen, F. Dai, M.L. Gordin, Z. Yu, Y. Gao, J. Song, D. Wang, Angewandte ChemieInternational Edition, 55 (2016) 4231-4235.[38] Y. Yang, G. Zheng, S. Misra, J. Nelson, M.F. Toney, Y. Cui, Journal of the American Chemical Society, 134 (2012) 15387-15394. [39] V.S. Kolosnitsyn, E.V. Kuzmina, E.V. Karaseva, Journal of Power Sources, 274 (2015) 203-210.

[40] S. Chen, F. Dai, M.L. Gordin, D. Wang, RSC Advances, 3 (2013) 3540-3543. 

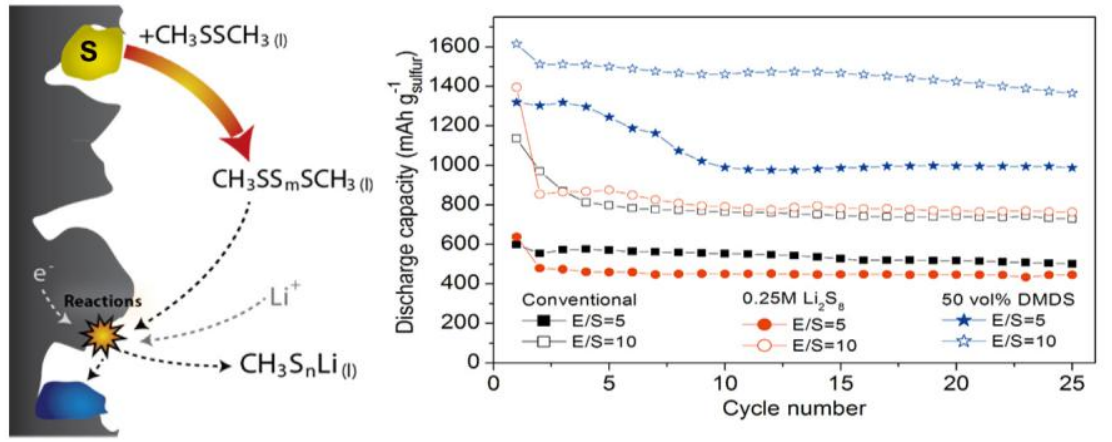